\title{
OS SERVIÇOS DE ÁGUA E ESGOTO NO ESTADO DO RIO DE JANEIRO: REGULAÇÃO E PRIVATIZAÇÃO
}

\author{
Gisela A. PIRES Do Rio ${ }^{1}$ \\ Departamento de Geografia \\ Universidade Federal do Rio de Janeiro e \\ Alba Valéria de S. Sales ${ }^{2}$
}

\section{Introdução}

O setor de água e saneamento no Brasil vem passando por transformações importantes nas duas últimas décadas. Até os anos de 1930, a estrutura do setor era privada. Essa estrutura começou a ser estatizada a partir do primeiro governo Vargas, permanecendo assim até os anos de 1980, quando se inicia uma reestruturação apoiada na privatização. Neste último período importantes mudanças foram operadas nos três segmentos do setor: funcionamento, organização institucional e desenvolvimento tecnológico (Silva, 2003). Em conjunto, essas mudanças significaram a condição para consolidação dessa indústria, compreendida, neste trabalho, como conjunto de atividades para as quais as relações técnicas e organizacionais condicionam a escala de operação, articulando, assim, mercado mundial, atividades de P\&D, serviços técnicos e controle da infra-estrutura pública. Em linhas gerais, essas mudanças foram possíveis em função da nova matriz institucional que emergiu a partir das reformas macroeconômicas do Estado nos anos de 1990.

\footnotetext{
I Professora Adjunta do Departamento de Geografia - UFRJ; giselario@ufrj.br.

${ }^{2}$ Aluna de Graduação do Curso de Geografia -UFRJ; albasales@ibest.com.br.
} 
O presente artigo propõe-se analisar os efeitos dessas mudanças no estado do Rio de Janeiro. Neste estado, as alterações nos fundamentos da estrutura de regulação vêm provocando modificações na organização dos serviços. No estágio atual, observa-se uma estrutura com três pólos: companhia estadual, companhias municipais e empresas privadas. Não obstante este "modelo" não estar ainda consolidado, ele pode propiciar alguns elementos de discussão sobre a dimensão espacial da nova lógica institucional e as interações que dela decorrem como a atuação de grupos privados, as estratégias que garantem o controle da infra-estrutura e asseguram as condições de produção e reprodução social.

A discussão que se segue está organizada em duas partes. Na primeira, discutese as características técnicas e os dispositivos gerais do modelo de regulação implantado no país. Nessa discussão foram tratados os seguintes itens: as especificidades dos serviços de água e esgoto, os modelos de concessão e as características das concessionárias. Na segunda parte, esses elementos serão aplicados ao estado do Rio de Janeiro, indicando-se o sistema de concessão adotado, as empresas nele envolvidas, as áreas atingidas e os ajustes nos termos de concessão decorrentes da pressão da sociedade civil.

\section{Especificidades da indústria em rede}

Nos termos da economia industrial, esses serviços pertencem à categoria de indústria em rede, isto é, indústrias que possuem uma organização de atividades de porte e estrutura interna diversificados e que estabelecem relações técnico-produtivas entre si (Angelier, 1991; Dantas et al, 2002). Nesse sentido, a indústria de água e saneamento comporta tanto empresas multifuncionais que articulam atividades de captação, tratamento, distribuição e re-utilização das águas, como aquelas exclusivamente dedicadas à operação de sistemas isolados.

As indústrias em rede caracterizam-se, igualmente, como sendo aquelas atividades/serviços para os quais o monopólio sobre a rede de infra-estrutura representa a condição necessária para a própria existência da atividade (Lévêque, 1998). O monopólio sobre a rede significa tanto a forma de controle sobre o acesso como também sobre o "estoque" de usuários, influenciando, portanto, no desenho e extensão da rede de infra-estrutura. O exercício do monopólio pode ser constituído em escala nacional, como o foi no caso da energia elétrica e da telefonia, ou em escala regional/local, como nos serviços de água e saneamento ou coleta e tratamento de lixo. Trata-se, assim, de uma estrutura organizada em torno das redes de distribuição ${ }^{3}$ e escoamento. Esse último aspecto foi decisivo para a consolidação

\footnotetext{
${ }^{3}$ No caso brasileiro, a insuficiência da cobertura da rede de abastecimento de água, permitiu a emergência de uma rede informal de distribuição por caminhões-pipa. Sistema semelhante é encontrado em outros países da Amércia Latina, notadamente Peru e Equador.
} 
do modelo adotado no Brasil, ou seja, os serviços de água e esgoto passaram a ser de competência do poder público, único agente capaz de alavancar recursos para suportar os elevados investimentos em capital fixo exigidos para implantação, operação e manutenção da rede.

Desses aspectos resultam, em grande parte, as especificidades das indústrias em rede. Sua qualidade de infra-estrutura implica em elevado grau de irreversibilidade no que tange à implementação do aparato técnico ${ }^{4}$. Esse ponto é importante, pois a implantação de uma rede de água e esgoto qualifica os espaços: em áreas urbanas a antecipação de infra-estrutura condiciona o ritmo de ocupação de um bairro, por exemplo. A expansão espacial da rede e seu pleno funcionamento dependem, por sua vez, da capacidade de conexão técnica e da densidade de usuários para assegurar sua rentabilidade. Assim, a densidade das redes de infra-estrutura está diretamente relacionada à concentração da população, à intensidade de uso e ao nível de atividade econômica. De modo bastante sintético, as redes apoiam-se na circulação como fonte geradora de valor. Para tanto, três condições para sua realização devem ser obedecidas: imediatidade, instantaneidade e conectividade (DUPUY, 1991). A primeira condição diz respeito ao acesso do usuário ao serviço, isto é, a qualquer momento, do dia ou da noite, o serviço deve estar disponível (ou deveria estar). A segunda refere-se ao tempo necessário para se obter o serviço, ou seja, não há lapso de tempo entre o momento de abrir a torneira e a água começar a correr (pelo menos é o que se espera!). A terceira condição constitui aquela que permite a realização das duas anteriores: se não houver uma rede física, o serviço não é prestado, donde a importância de se conhecer o desenho espacial da rede, sua orientação e a direção de sua de expansão.

Como as demais indústria em rede, os serviços de água e saneamento estão associados à implantação de um modelo de regulação que estabeleceu as novas regram que passaram a reger as relações estado-mercado. As mudanças institucionais que asseguram a progressão da acumulação exigem, portanto, a adequação dos mecanismos de regulação (BOYER 1986; BOYER e SAILLAND, 1995). Observa-se, em decorrência, um duplo movimento: de um lado o Estado concentra-se na própria regulação dos serviços privatizados e na garantia do "ambiente" competitivo entre agentes; do outro, observa-se a re-organização das empresas envolvidas no processo de privatização (PIRES DO RIO et al, 2002). Consideradas em seu conjunto, essas normas estruturam as opções de gestão dos recursos hídricos, as decisões e as estratégias das diferentes organizações, públicas e privadas, que operam os serviços. Em outros termos, estamos diante de uma mudança da lógica institucional com dispositivos para regular os serviços concedidos. A questão reside no aspecto da introdu-

\footnotetext{
${ }^{4}$ A dimensão física consiste no conjunto de pontos de captação, tubulações, estações elevatórias e de tratamento e de linhas que permitem identificar o grau de conectividade e acessibilidade de áreas e consumidores à rede.
} 
ção da concorrência na prestação dos serviços de água e esgoto. As modificações introduzidas pelo atual modelo indicam uma tendência à concentração, isto é, as companhias municipais estão sendo substituídas por empresas privadas pertencentes ao mesmo grupo. As características da rede, apontadas anteriormente, são apresentadas como argumentos técnicos que dificultam a realização de concorrência nos municípios. A partir do momento em que a mesma já está, em sua maioria, montada, dificulta-se a atuação de mais de um operador/prestador em uma mesma área. Dessa forma, a concorrência vai ocorrer no processo de licitação e não posteriormente, como no caso da telefonia, no qual o usuário pode escolher a operadora que lhe prestará o serviço. Nesse sentido, o estado do Rio de Janeiro constitui um exemplo bastante ilustrativo do processo que vem ocorrendo.

No caso da indústria de água e saneamento, é possível observar que esses dispositivos gerais buscam atender a dois princípios essenciais:

a) articulação pelo poder público entre demanda e expansão da rede, respeitadas as restrições de financiamento que repercutem na rentabilidade das empresas, e

b) gestão dos recursos que estão na origem, isto é, a gestão dos recursos hídricos envolve mais agentes do que aqueles que operam os serviços de água e saneamento.

A necessidade de articulação impõe-se pela nova posição do poder público. Como se afasta da prestação direta do serviço, a ele cabe, via agência reguladora, assegurar a coordenação das atividades afim de evitar a falta ou a dificuldade de atendimento às demandas sociais. Os efeitos de uma situação de crise tendem a repercutir no âmbito da esfera pública, exigindo rigor ou flexibilidade (dependendo da situação) nos dispositivos de regulação. A mudança institucional, como resposta à situação anterior geralmente caracterizada pela incapacidade do poder público em exercer a função de prestador direto do serviço, exige habilidade e canais específicos ainda não completamente consolidados para resolver tensões entre usuários e empresas. Observa-se que o Ministério Público vem sendo frequientemente acionado, como interlocutor privilegiado dos usuários e mediador dos conflitos.

As modificações acima mencionadas resultam da implantação do modelo de gestão dos recursos hídricos ${ }^{5}$. Nesse modelo, a adoção da bacia hidrográfica tem implicações importantes para a gestão. As bacias hidrográficas foram adotadas como unidades de gestão e pressupõem a criação de Comitês de Bacias, cujas principais funções são racionalizar o uso, a quantidade de água disponível para cada categoria de consumidor (residencial, comercial e industrial) e a qualidade da água consumida. Esses comitês congregam ainda as funções de financiamento direto

\footnotetext{
${ }^{5}$ A Política Nacional de Recursos Hídricos definida pela Lei 9.433, de 1997, adotou os seguintes, princípios: usos múltiplos da água, cobrança pelo seu uso, outorga do direito de uso, bacia hidrográfica como unidade de gestão, descentralização da gestão dos recursos hídricos.
} 
(projetos de engenharia em redes de distribuição e de saneamento, de educação ambiental, de conformidade com as normas ambientais nacionais e européias), de apoio e assistência aos municípios integrantes de uma mesma bacia no que tange à gestão dos recursos hídricos (proteção e preservação dos recursos, prevenção de contaminação por fontes difusas de poluição, acesso ao recurso, conhecimento do meio) e de fórum de negociação para os conflitos entre atores integrantes da mesma bacia. Evidencia-se, desse modo, a ampliação do quadro da gestão que inclui interações entre um leque variado de agentes.

\section{Os modelos de Concessão}

De modo simplificado, considera-se que existem dois sistemas de prestação de serviços de saneamento: a) através das Companhias Estaduais de Saneamento Básico (Cesbs), empresas de economia mista, cuja responsabilidade por esses serviços inclui as atividades de operação e administração, mediante concessão legal dos municípios que ficariam, por sua vez, com as atribuições de fiscalização, podendo rescindir o contrato mediante apresentação de justificativa e b) os próprios municípios oferecem os serviços de distribuição de água e coleta de esgoto, sendo denominados Municípios Autônomos em Serviços de Água e Esgoto que, em caso de concessão à iniciativa privada, tornam-se responsáveis pela fiscalização da qualidade dos serviços e do cumprimento das cláusulas contratuais (BRITTO e PORTO, 2000).

Os processos de concessão vêm sendo regidos pela Lei 8.987, de 13 de fevereiro de 1995, do Regime de Concessões e Permissão da Prestação dos Serviços Públicos, que prevê que a delegação da prestação do serviço deve ser feita pelo poder concedente (União, Estado ou Município), mediante licitação, na modalidade de concorrência, à pessoa jurídica ou consórcio de empresas que demonstre capacidade para seu desempenho, por sua conta e risco e por prazo previamente determinado, o que pressupõe a prestação de serviço adequado ao pleno atendimento dos usuários, em termos de regularidade, continuidade, eficiência, segurança e modicidade nas tarifas.

Outro instrumento legislativo pertinente ao setor é o Projeto de Lei ${ }^{0}$ 4.147/2001, em tramitação, que traça diretrizes para a prestação dos serviços de saneamento básico. Se aprovado, o projeto de lei pode vir a complementar a Lei das Águas (9.433/97), pois prevê a articulação entre o Sistema Nacional de Informações em Saneamento e o Sistema Nacional de Recursos Hídricos e (re)organiza o setor com base em bacias hidrográficas. A votação deste projeto está sendo aguardada por empresas que desejam investir no setor de saneamento, na medida em que a esse instrumento é conferido o papel de estimular a competitividade, e considerado como mecanismo mais claro de regulação ${ }^{6}$. 
Segundo Hespanhol (1999), existem níveis diferenciados de concessões os quais vão depender do grau de envolvimento do capital privado na operação. Estas modalidades ${ }^{7}$ estão divididas em dois grupos, a saber:

I) Ativos que permanecem em poder público:

- Contrato de serviço - terceirização de alguns serviços periféricos como manutenção e leitura de hidrômetros. A total responsabilidade pelos serviços ficam com o poder público, salvo os serviços terceirizados;

- Contrato de operação - a companhia privada assume a responsabilidade total pela operação e manutenção de um determinado sistema. A responsabilidade financeira continua com o poder público e a empresa contratada atua como representante deste poder;

- Contratos de leasing - locação, por parte de entidade privada, de instalações do setor público por um determinado período. A empresa locatária assume a responsabilidade por novos investimentos;

- Contratos de concessão - a entidade privada ou concessionária assume total responsabilidade pelos serviços. Os ativos permanecem como propriedade do poder público mas fica sob a responsabilidade do capital privado durante a duração do contrato;

II)Transferência de parte ou totalidade dos ativos:

- Concessão de margem - a empresa ou consórcio de empresas financia, constrói e opera um sistema e o transfere, ao final do prazo de contrato, ao poder público;

- Concessão inversa - o poder público financia e constrói o sistema e estabelece um contrato com o capital privado para sua operação. A empresa, ao se interessar, pode adquirir o sistema mediante amortização durante o contrato;

- Empresas de economia mista - geralmente são sociedades anônimas que atuam como intermediárias nas etapas iniciais de processos de privatização onde há resistência contra a entrada de capital privado na prestação dos serviços;

- Privatização total - venda completa de todos os ativos ao capital privado que se responsabiliza pela totalidade das atividades referentes ao setor.

O nível mais utilizado no Brasil é o modelo de concessão segundo o qual os ativos continuam a pertencer o poder público e a concessionária torna-se responsável, durante um prazo que pode variar de 15 a 30 anos, por todos os serviços, desde a operação à gestão, passando pela ampliação e modernização dos serviços. Dentro

\footnotetext{
${ }^{6}$ Do ponto de vista das empresas a ausência de instrumentos claros de regulação é considerada um dos fatores de aumento de risco para os investimentos.

${ }^{7}$ As características das modalidades de concessões existente foram exploradas em Pires do Rio et al (2002).
} 
desta modalidade há as opções de concessões plenas (água e esgoto) ou parciais (somente água ou esgoto). No caso da chamada subconcessão dos serviços de esgoto, há ainda a possibilidade de subdivisão do sistema podendo a concessionária operar somente a coleta ou somente o tratamento dos resíduos.

Há alguns fatores bastante relevantes que se apresentam como obstáculos ao desenvolvimento do processo de concessão dos serviços de saneamento básico. $\mathrm{O}$ primeiro refere-se à questão da titularidade ${ }^{8}$, o que obriga os processos de concessão a dependerem de acordos entre diferentes esferas de poder, com interesses distintos e com representações diferenciadas. O projeto de lei 4.147/2001 admite o Município como poder concedente dos serviços de interesse local (quando as atividades visam atender apenas a um município) e o Estado, nos serviços de interesse comum (quando os serviços buscam o atendimento de mais de um município), exceto os de gestão associadas através de convênios ou consórcios públicos entre os titulares dos serviços. Além da titularidade, os fatores apontados como restritivos à entrada de empresas privadas são:

a) ausência de mecanismos claros de regulação o que pode aumentar os riscos para as empresas - a atividade de regulação é exercida de forma diferente em cada concessão. Nos casos de Limeira-SP e Petrópolis-RJ, as antigas concessionárias, que eram as Companhias Municipais de Saneamento, sem mudança alguma em sua estrutura, tornaram-se responsáveis pelo exercício regulatório. Nos casos das concessões obtidas pelas empresas Prolagos e Águas de Jurtunaíba, ambas no Estado do Rio de Janeiro, por atuarem em mais de um município, o poder concedente foi partilhado entre Estado e Municípios, diferentemente de outras concessões no Brasil. Essas empresas estão submetidas ao aparato regulatório da Agência Reguladora dos Serviços Públicos Concedidos - ASEP (Mello, 2001);

b) indefinição dos critérios constantes dos editais de licitação. De acordo com a Lei 8987/95, os editais devem expor, de forma clara, os critérios para a escolha das propostas, observando os princípios de legalidade, moralidade, publicidade e igualdade face os seguintes pontos: i) menor tarifa a ser cobrada pela prestação dos serviços; ii) maior oferta pela outorga da concessão; iii) melhor combinação dos dois itens anteriores (quando previamente estabelecidos no edital); iv) melhor proposta técnica.

\footnotetext{
${ }^{8}$ Titular ou poder concedente de um determinado serviço é aquele a quem a lei atribui competência para sua prestação. De acordo com a Constituição Federal, o município é titular dos serviços de água e esgoto desde que os mesmos se prestem ao atendimento de um único município, porém, há controvérsias quando trata-se de município de região metropolitana, onde não há clareza quanto à titularidade, o que provoca conflitos entre os poderes estadual e municipal, como no município de Niterói, Rio de Janeiro, onde a concessionária Águas de Niterói precisou aguardar dois anos e quatro meses para entrar em operação devido uma ação movida pelo governo estadual, contestando a titularidade da prefeitura (PARLATORE, 2000).
} 
Alguns municípios adotam como critério principal o item maior oferta pela outorga da concessão, o que acaba onerando a concessionária e evitando que menores tarifas sejam cobradas e haja reversão de benefícios aos usuários.

\section{Características das concessionárias}

Considerando-se o princípio de concorrência, explícito no modelo das concessões, o mais adequado seria a participação de um número considerável de empresas no processo de licitação, porém, algumas cláusulas dos editais, aliadas às indefinições do marco regulatório, são apontadas como limitadoras ao número de participantes. A avaliação da confiabilidade das concorrentes é uma delas, pois é da competência do titular dos serviços estipular o capital mínimo das empresas aptas a concorrer. Trata-se de uma forma de garantir que a empresa que obtenha a concessão disponha de capacidade financeira e poder de endividamento para assegurar os investimentos a serem realizados ${ }^{9}$. Considerando que no Brasil não existem muitas empresas com experiência em serviços de água e esgoto, uma vez que os mesmos foram, ao longo dos últimos 30 anos, prestados pelo poder público, empresas de menor porte acabam sendo impedidas de participar dos processos licitatórios. Sua participação fica condicionada à realização de consórcios ou associações com empresas estrangeiras especializadas no setor, posto que a legislação brasileira não veta totalmente a participação de capital internacional.

É o caso de algumas concessões que envolvem utilities (empresas especializadas na prestação de serviços públicos) estrangeiras como o grupo francês Suez Lyonnaise des Eaux que, através da subsidiária Ondeo, atua no município de Limeira-SP, juntamente com a CBPO- Companhia Brasileira de Projetos e Obras, do grupo baiano Odebrecht e no município de Manaus, onde atua sem parceria com capital nacional. A Suez está presente em mais de 20 países como operadora de sistemas de água e esgoto. Ainda no grupo de empresas internacionais que atuam no Brasil, deve-se mencionar a Vivendi (francesa), Thames Water (inglesa), Águas de Portugal, Tyco Engenharia (ambas portuguesas) e a americana CH2M Hill.

Uma alternativa à união com capital estrangeiro é a formação de consórcios por grandes grupos empresariais consolidados, geralmente do setor de engenharia e construção de infra-estrutura como Andrade Gutierrez, Camargo Correia, Queiroz Galvão, Odebrecht, entre outras. É a concentração em torno destes grandes grupos que compõe o quadro de concessões nacionais (Quadro 1$)^{10}$.

\footnotetext{
${ }^{9}$ A Lei de Concessões apresenta, no $\S 3^{\circ}$, art. 15, que o poder concedente deve recusar propostas manifestamente inexeqüíveis ou financeiramente incompatíveis com os objetivos da licitação, porém, a estipulação de valor de capital mínimo vai depender das considerações do concedente.

10 A empresa Monteiro Aranha participou do consórcio Prolagos durante o período de licitação. Atualmente, quem opera os serviços na região, através da Prolagos, é a Águas de Portugal.
} 
Quadro 1 - Principais grupos que obtiveram concessões, suas sedes, atividades e municípios nos quais operam.

\begin{tabular}{|c|c|c|c|}
\hline Grupo & Sede & Atividades Principais & Área de Concessão \\
\hline C.R. Almeida & $\mathrm{RJ}$ & $\begin{array}{l}\text { Construção, logística, química } \\
\text { e petroquímica, comércio exterior, } \\
\text { comércio atacadista }\end{array}$ & Jaú-SP \\
\hline Camargo Corrêa & SP & $\begin{array}{l}\text { Construção, mineração, metalurgia, } \\
\text { logística, saneamento, equipamentos } \\
\text { elétricos, têxtil, pecuária, } \\
\text { agricultura e transportes }\end{array}$ & Itu-SP \\
\hline Carioca Engenharia & RJ & Construção & $\begin{array}{l}\text { Campos-RJ, } \\
\text { Niterói-RJ e } \\
\text { Paranaguá-PR }\end{array}$ \\
\hline Monteiro Aranha & $\mathrm{RJ}$ & $\begin{array}{l}\text { Material eletrônico, seguros, } \\
\text { telecomunicações }\end{array}$ & $\begin{array}{l}\text { Arraial do Cabo, } \\
\text { Búzios, Cabo Frio, } \\
\text { São Pedro da Aldeia e } \\
\text { Iguaba (RJ) - Prolagos }\end{array}$ \\
\hline Multiservice Engenharia & SP & $\begin{array}{l}\text { Construção, saneamento, } \\
\text { meio ambiente }\end{array}$ & $\begin{array}{l}\text { Araçatuba, Jaú, } \\
\text { Cajamar, } \\
\text { Ourinhos-SP. } \\
\text { Além de prestar } \\
\text { 'serviços para a } \\
\text { Sabesp-SP, Cedae-RJ } \\
\text { e gerenciar obras de } \\
\text { ETE Alegria, Baía de } \\
\text { Guanabara-RJ }\end{array}$ \\
\hline Odebrecht & $\mathrm{BA}$ & $\begin{array}{l}\text { Construção, energia elétrica, } \\
\text { agricultura }\end{array}$ & Limeira-SP \\
\hline Queiroz Galvão & $\mathrm{RJ}$ & $\begin{array}{l}\text { Construção, energia elétrica, } \\
\text { agricultura }\end{array}$ & $\begin{array}{l}\text { Araruama, Silva } \\
\text { Jardim e Saquarema } \\
\text { (Águas de Jurtunaíba), } \\
\text { Campos, Niterói e } \\
\text { Petrópolis-RJ }\end{array}$ \\
\hline Tejofran & SP & $\begin{array}{l}\text { Segurança pessoal e patrimonial, } \\
\text { saneamento, telecomunicações, } \\
\text { energia elétrica, controle de } \\
\text { tráfego, concessões }\end{array}$ & Araçatuba e Jaú-SP \\
\hline
\end{tabular}

Fonte: Gazeta Mercantil S.A. Balanço Anual, junho/2002; ABCON. Concessōes privadas em operação, setembro/2002.

Assim, como as utilities estrangeiras, os grupos que participam das concessões estão traçando estratégias de diversificação de atividades. O grupo Queiroz Galvão atua nos setores de construções, energia elétrica, agricultura e criou a Queiroz Galvão Parts. Concessões S/A através da qual compõe, juntamente com mais quatro empresas, a holding Águas do Brasil, responsável pelas concessões de Águas 
do Imperador, Águas de Jurtunaíba, Águas do Paraíba e Águas de Niterói, no Rio de Janeiro, além da Águas de Paranaguá, no Paraná.

Este cenário fortalece o que foi exposto anteriormente quanto à vantagem das grandes empresas nas licitações. No entanto, essas empresas devem se adequar às características específicas destes serviços e da área concedida, considerando os riscos envolvidos na operação que giram em torno do atendimento à demanda efetiva e à demanda reprimida.

Ao assinar um contrato para operação em determinado município, a concessionária geralmente considera os seguintes pontos:

a) o acesso ao bem principal - no caso dos serviços de saneamento, a água;

b) rede sobre a qual se desenvolverá todas as atividades técnicas e de produção;

c) acesso às fontes - que na maioria das vezes é de responsabilidade da esfera estadual e não municipal como a titularidade dos serviços;

d) risco de rescisão de contrato - não obstante a legislação prever indenização nestes casos, este é considerado um fator de alto risco, que deve ser minimizado com a formulação de mecanismos efetivos e bem definidos de regulação;

e) retorno financeiro no médio e longo prazo;

f) nível de concentração populacional que justifique os investimentos a serem feitos;

g) desigualdades no acesso aos serviços, entre áreas geográficas.

Deve-se lembrar, ainda, que apesar de no meio urbano grande parte da estrutura de abastecimento já estar montada e existir um significativo número de ligações/economias " ${ }^{11}$ é também nesta região que encontra-se a maior concentração de pessoas que não podem pagar altas tarifas pela prestação dos serviços, constituindo, no entanto, uma demanda reprimida.

A necessidade de grandes investimentos e o retorno que pode ser alcançado no longo prazo de operação ocorre, principalmente, no caso de concessões de serviços de coleta e tratamento de esgotos que requerem a construção de ETEs (estações de tratamento de esgoto). Aquele seguimento oferece menor margem de retorno e apresenta, atualmente, o menor índice de cobertura, em todo Brasi ${ }^{12}$. Se, por um lado, a necessidade de grandes investimentos para a expansão da rede e o atendimento à demanda pelos serviços constituem fatores que reduzem a margem de retorno para o capital privado, por outro, a possibilidade de aumento de produtividade e eficiência, diminuição do desperdício, combate às ligações clandestinas e a existência de um mercado cativo traduzem, por sua vez, fatores de

\footnotetext{
1 Uma ligação significa a conexão de uma construção à rede geral de abastecimento. Esta construção pode ser uma casa, prédio, empresa. Cada economia equivale à entrada de abastecimento direto para cada residência. Como exemplo bastante simples, consideremos um prédio de cinco andares, com 5 apartamentos por andar, totalizando 25 apartamentos. Este prédio possui uma ligação (prédio) e 25 economias (apartamentos). Já uma casa que esteja diretamente conectada à rede geral de abastecimento é considerada uma ligação/economia (MELLO, 2001).
} 
atração. Esses últimos significam, para as empresas, custos que serão plenamente recuperados. O número de empresas interessadas em atuar no setor vem crescendo e a demonstração deste interesse foi a criação, em agosto de 1996, da ABCON - Associação Brasileira das Concessionárias de Serviços Públicos de Água e Esgoto, que congrega 44 empresas da iniciativa privada que operam, ou pretendem operar, no setor.

\section{O Estado do Rio de Janeiro}

O Estado do Rio de Janeiro apresenta fortes desigualdades nas condições de abastecimento de água e tratamento de esgoto, sobretudo se comparadas as taxas de cobertura desses serviços nos municípios que compõem a região metropolitana e aquelas das demais macrorregiões do estado. Ao se comparar a região metropolitana com a região da baixada litorânea, por exemplo, verifica-se uma significativa disparidade nos percentuais de domicílios ligados às redes de abastecimento de água e esgotamento sanitário. Segundo o Anuário Estatístico do estado do Rio de Janeiro, no ano de 1980, 66,7\% dos domicílios da região metropolitana eram ligados à rede geral de abastecimento de água da CEDAE e 53\% dos domicílios eram ligados à rede de esgotamento sanitário. No mesmo ano, os municípios da baixada litorânea apresentavam 56,2\% de seus domicílios ligados à rede de abastecimento de água, porém, não havia informações sobre domicílios ligados à rede de esgoto. Em 2000, a região metropolitana do Rio de Janeiro apresentava $63,4 \%$ de seus domicílios ligados à rede de água e 40,3\% com esgotamento sanitário. Já na região da baixada litorânea, apenas 45,6\% dos domicílios estão ligados à rede de abastecimento e 3,9\% possuem esgotamento sanitário (CIDE, 2001). Essa diferença explica-se, em parte, pela intensidade de capital exigida por esses investimentos: muitos municípios não dispõem de recursos financeiros para implantação desses serviços. Não obstante o quadro de escassez de recursos financeiros nesse nível de administração, há que se reconhecer que ele não é suficiente para explicar as desigualdades encontradas. A distribuição espacial dos serviços retrata padrões de investimento e de valorização de determinadas áreas em detrimento de outras. Agentes imobiliários e o próprio Estado têm grande capacidade para direcionar os investimentos em infra-estrutura de água e esgoto (BRITTO, 1995) ${ }^{13}$, criando, assim, fortes disparidades entre as diferentes áreas.

\footnotetext{
12 Atualmente existem 5.507 municípios no Brasil, dos quais $97,9 \%$ são atendidos pelos serviços de abastecimento de água, enquanto apenas $63,9 \%$ possuem esgotamento sanitário. É importante lembrar que o fato de o município dispor de esgotamento sanitário, não significa que o mesmo esteja ligado a uma rede regular e sim que dispõe de qualquer tipo de serviço de esgotamento (IBGE, 2000).

${ }_{13}$ Esse aspecto é amplamente discutido em Geografia Urbana. Não cabe neste trabalho explicitar toda a complexidade do problema.
} 
Nesse quadro de contrastes, alguns municípios tomaram a iniciativa de abrir os serviços de água e esgoto ao capital privado através de concessões. A distribuição espacial dessas iniciativas é analisada mais adiante. Cabe destacar, no momento, que os resultados delas decorrentes apontam para uma mudança em termos da estrutura organizacional. Nesse sentido, é possível detectar três categorias de municípios: municípios atendidos pela CEDAE; municípios que efetuaram concessões para a iniciativa privada e municípios autônomos na prestação dos serviços de água e esgoto.

Um dos exemplos do que acaba de ser mencionado foi encontrado nos municípios da Região dos Lagos que efetuaram contratos com empresas privadas. Essa região possui sérios problemas de disponibilidade de água, o que prejudica algumas das atividades econômicas locais, principalmente aquelas apoiadas na exploração do seu potencial turístico. Em abril de 1998, os municípios de Arraial do Cabo, Búzios, Cabo Frio, Iguaba Grande, e São Pedro da Aldeia, concederam, através de consórcio por eles formado, os serviços de água e esgoto à Prolagos, concessionária formada pelas empresas Águas de Portugal, Monteiro Aranha, Bozano Simonsen e PEM Engenharia. A Prolagos apresentava o perfil descrito anteriormente da maioria das concessionárias, segundo o qual empresas de construção civil se aliam ao capital internacional, através de subsidiárias especializadas em serviços de saneamento. Outro exemplo consiste na Tyco Engenharia, empresa portuguesa que opera no município de Nova Friburgo através da Earth Tech Brasil. Nos demais municípios onde foram efetuadas concessões, as concessionárias são compostas por capital nacional de grandes empresas, como mostra o Quadro 2.

Observando as informações expostas no quadro acima, conclui-se que o mesmo grupo de empresas atua em quatro concessões. Essas empresas integram a holding Águas do Brasil, citada anteriormente. Formada pelas empresas Erco Engenharia, Queiroz Galvão, EIT, Developer e Construtora Cowan, que também opera em Paranaguá, no Estado do Paraná, a holding Águas do Brasil representa o fortalecimento da participação de empresas de engenharia e construção nessa indústria e aponta para um quadro de concentração em torno desses grupos, no estado do Rio de Janeiro. Como tendência geral, considera-se que essa concentração possa constituir uma barreira à efetiva competição para os investimentos necessários à ampliação dos serviços. Além disso, esse quadro pode converter-se em benefícios para este grupo nos processos concorrenciais na medida em que passam, com mais facilidade, a atender aos critérios das cláusulas de licitações, como princípios de solidez financeira aliada à experiência no setor, conforme já salientado.

O mapa abaixo mostra, em detalhe, a distribuição espacial segundo o modelo de exploração/concessão dos serviços de água e esgoto no estado do Rio de Janeiro. O mapa constitui um retrato da situação em 2002 que permite identificar três modelos, segundo um padrão polarizado entre a região do médio vale do rio Paraíba do Sul e a região litorânea e, entre essas duas, uma grande área que permanece sob controle da CEDAE. Observa-se, assim, duas estratégias distintas encon- 
Quadro 2 - Concessões de água e saneamento ao capital privado, no estado do Rio de Janeiro, por município, empresas, operadora, modelos de concessão, data do contrato, prazo de concessão e valor dos investimentos.

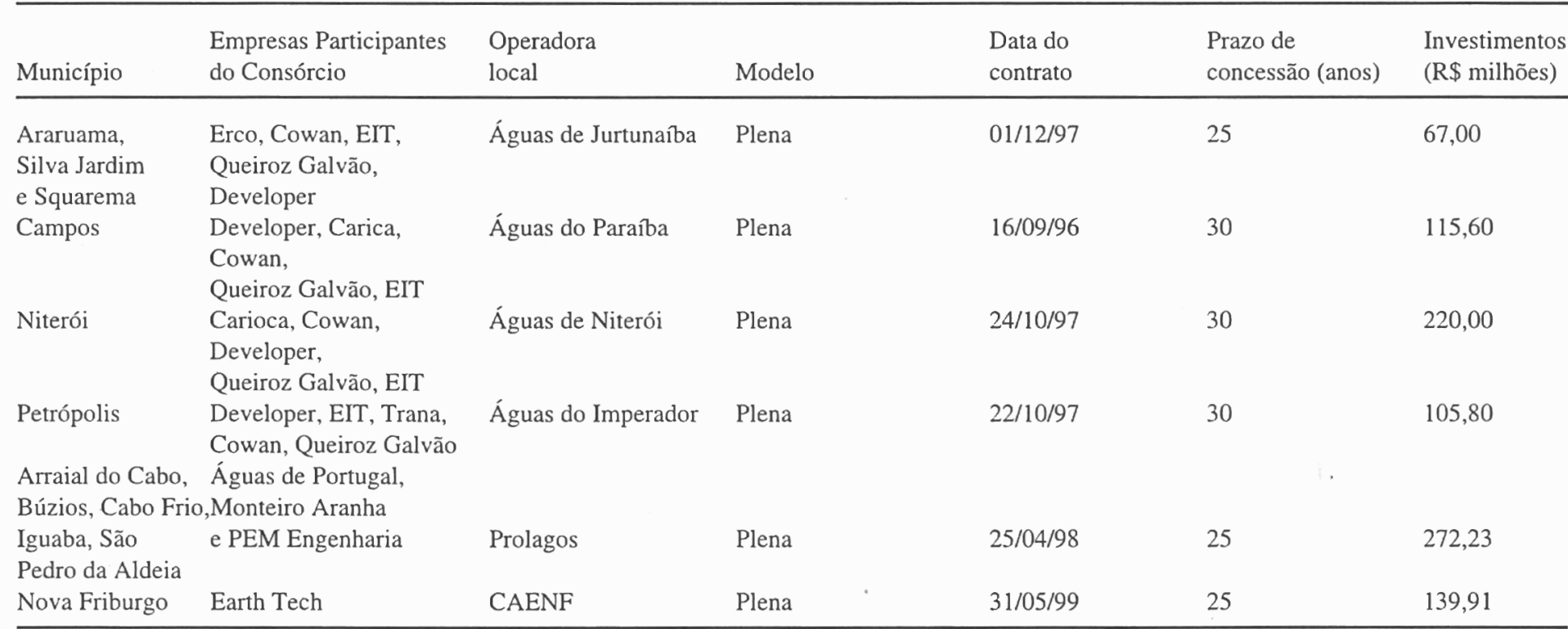

Fonte: ABCON - Concessōes Privadas em Operação, setembro/2002. 
tradas pelos municípios. Por um lado, para os autônomos, concentrados no médio Paraíba do Sul, existem duas hipóteses que podem justificar a decisão de assumir a responsabilidade pelos serviços: a primeira é a de que algumas prefeituras possuem capacidade de investimento para saldar o déficit de infra-estrutura existente em seu município ${ }^{14}$ e a segunda, seria a adoção de políticas públicas municipais voltadas para o atendimento de demandas por serviços básicos, mas que revelariam indícios de estratégias políticas no sentido de manter e expandir o poder sobre o território. Uma hipótese não exclui a outra, podendo haver o somatório dos fatores. Essas hipóteses são reforçadas pelo fato de que, nesses municípios, não foram encontrados os consórcios intermunicipais, arranjo organizacional predominante em outras regiões, como, por exemplo, no estado de São Paulo. Por outro lado, a baixada litorânea, que possui problemas na cobertura das redes de água e esgoto, apesar da relativa autonomia, não dispõe de capacidade de financiamento para suprir a demanda existente no setor, que tende a se agravar em períodos de alta temporada turística. Dessa forma, os municípios de Araruama, Silva Jardim e Saquarema, e Arraial do Cabo, Buzios, Cabo Frio, Iguaba e São Pedro da Aldeia formaram dois consórcios intermunicipais que concederam os serviços de água e esgoto (com exceção da prefeitura de Arraial do Cabo, que continua responsável pelo sistema de água) a duas operadoras privadas: Águas de Jurtunaíba (holding Águas do Brasil) e Prolagos (Águas de Portugal), respectivamente. Esta região apresenta fatores de atração na medida em que as empresas, nacionais e internacionais, ali identificam um mercado efetivo e potencial que justifica o investimento: crescimento demográfico, expansão urbana, dinâmica do setor de construção associada às indústrias do turismo e pára-petrolífera. Efetivamente, ao longo dessa faixa, é possível observar o início de um processo de conurbação, sobretudo ao longo da rodovia Amaral Peixoto.

Na faixa diagonal do estado, cuja predominância é a operação da CEDAE, não foi, ainda, identificada a formação de consórcios de prefeituras, no entanto, o prazo de concessão dos serviços está próximo do fim e há fortes possibilidades de não renovação, face a incapacidade de investimentos verificado nas companhias estaduais ${ }^{15}$. Os processos de privatização de companhias inteiras - o que favorece a formação de monopólios regionais - leva a crer que estes municípios, após o término do contrato com a CEDAE, irão conceder seus serviços à iniciativa privada ou assumir a responsabilidade pelos mesmos. Considerando que parte destes muni-

\footnotetext{
${ }^{14}$ Os municípios de Volta Redonda e Barra Mansa, cuja economia baseia-se na siderurgia e metalurgia, são bons exemplos.

${ }^{15}$ Basta lembrar os seguidos anúncios de privatização das Cesbs, em todo o Brasil. Em fevereiro havia, sob o acompanhamento do BNDES, quatro empresas em processo de privatização: a da Bahia, de Pernambuco, Rio Grande do Norte e Espírito Santo (www.bndes.gov.br. Posição de privatizações em andamento em 07/02/2003).
} 


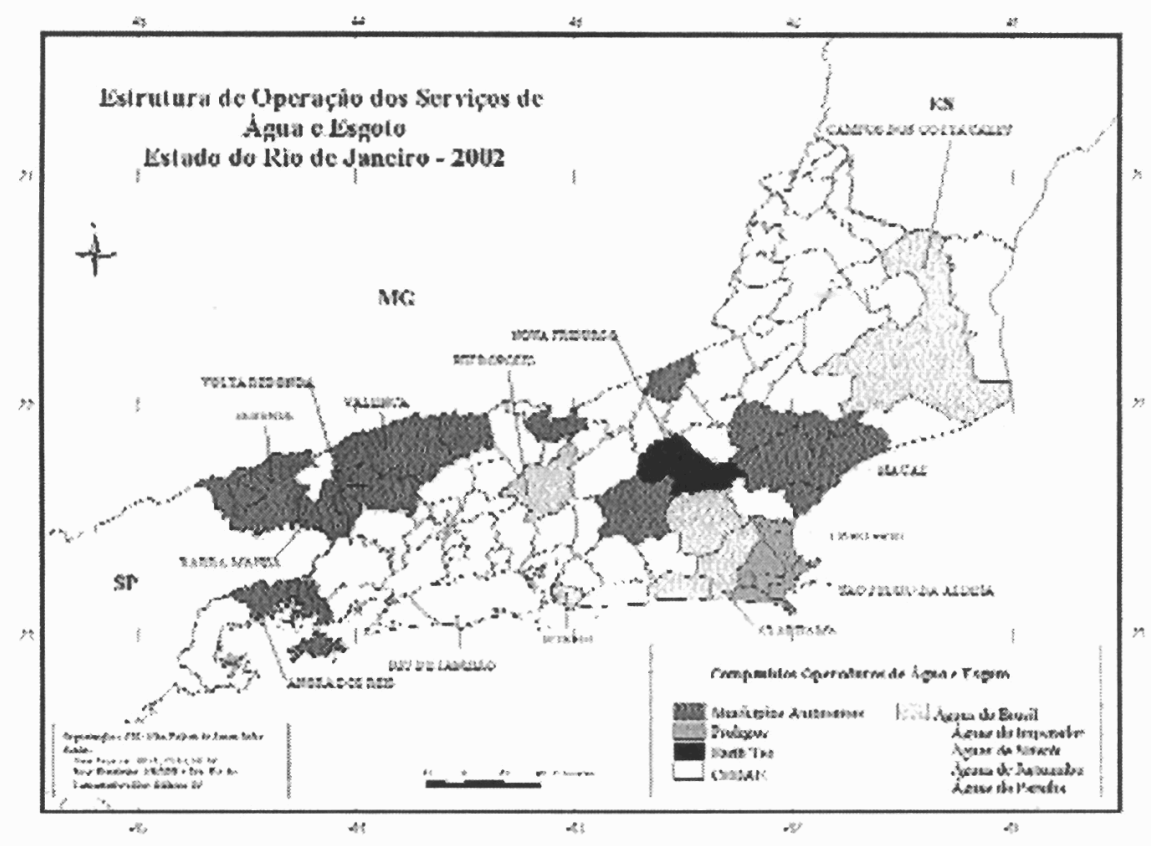

cípios encontra-se na região metropolitana, o expressivo número de usuários cativos aliado à extensão da rede já instalada traduzem chances de atração para o capital privado, levando à expansão horizontal desses grupos, que já atuam no estado.

As características dos serviços de água e esgoto traduzem dificuldades de práticas concorrenciais. $\mathrm{O}$ fato da rede física sobre a qual as atividades se realizam estar previamente montada dificulta a operação por mais de uma empresa para o mesmo grupo de usuários, constituindo, desta forma, uma situação de monopólio. A holding Águas do Brasil, através das empresas Águas do Paraíba e Águas do Imperador, operam em duas concessões dentro da mesma bacia hidrográfica, a do rio Paraíba do Sul. Lembrando o que foi apresentado anteriormente sobre o projeto de lei de saneamento básico, este setor está sendo reorganizado com base na bacia hidrográfica como unidade de gestão. A legislação do estado, em consonância com a legislação federal, admite a bacia hidrográfica ou região hidrográfica como unidade de gestão dos recursos hídricos, o que pode significar mais um ponto a ser explorado pela holding. No caso das empresas e consórcios que já atuam no setor, há um conjunto de fatores como: força econômica, experiência, capacidade de investimento, eficiência na operação, proximidade de áreas concedidas, número de usuários potenciais que, com combate ao desperdício e às ligações clandestinas, e 
expansão da rede de abastecimento maximizam o retorno financeiro, no médio prazo, e propiciam a formação de monopólios regionais.

É comum encontrar justificativas, para concessões a empresas privadas, centradas em torno da autonomia dos municípios em relação à prestação de serviços dessa natureza. Em trabalho de campo realizado nos municípios de Campos, Cabo Frio, Arraial do Cabo e Araruama pôde ser constatado que, para muitos representantes de órgãos públicos e para a população, a concessão dos serviços de água e esgoto constitui uma afirmação da autonomia do nível loćal em relação ao estado do Rio de Janeiro. Nos municípios cobertos pela Prolagos, por exemplo, houve conflitos que ultrapassaram a afirmação de autonomia como ruptura das relações verticais entre níveis de governo. As pressões de ONGs locais, como a VIVA LAGOA e RESSURG NCIA e do Consórcio Intermunicipal Lagos São João obtiveram alterações de cláusulas contratuais: os ganhos foram obtidos na antecipação das obras de saneamento a serem efetuadas pela empresa ${ }^{16}$

Com a reestruturação do setor, surge a necessidade de eficientes mecanismos de regulação para arbitrar sobre conflitos e para garantir serviços de qualidade e em quantidade apropriada às necessidades da população do município concedente. Nas concessões operadas pela Prolagos e Águas de Jurtunaíba, quem exerce a atividade de regulação é a ASEP - Agência Reguladora dos Serviços Públicos Concedidos do Rio de Janeiro, que regula, além dos serviços de água e esgoto, os setores de transporte e energia elétrica. A ASEP regula apenas estas duas concessões por tratarem de consórcio entre municípios, implicando, no ato da concessão, a partilha entre municípios e estado, da titularidade dos serviços. Nas demais concessões o próprio município exerce a atividade de regulador.

\section{Considerações finais}

Ao longo deste trabalho tentou-se mostrar que as mudanças institucionais estabeleceram e estruturaram um novo modelo para as relações entre organizações, empresas, atores coletivos e administração em seus diferentes níveis. Essas mudanças envolvem novos procedimentos administrativos e novas maneiras de se combinar estratégias de coordenação para ampliar a oferta e garantir o acesso aos serviços públicos concedidos, particularmente no que tange aos serviços de água e esgoto.

Observou-se, de um lado, que esses serviços estiveram sob controle diferente: enquanto os serviços de água estavam, em geral, a cargo dos estados, os serviços

\footnotetext{
${ }^{16}$ A principal alteração contratual foi a antecipação dos investimentos em esgotamento sanitário que deveriam ser feitos pela Prolagos. No contrato, a operadora somente deveria se preocupar com esgoto a partir de 2006. Com a repactuação da concessão, este limite passou para 2003.
} 
de esgoto integravam a responsabilidade dos municípios. No estado do Rio de Janeiro, as concessões que foram realizadas apontam uma tendência à combinação desses dois segmentos.

Por outro lado, as implicações da distribuição espacial analisada podem ser sintetizadas em dois pontos. Em primeiro lugar, os municípios que abriram espaço para a realização de contratos de concessão, como aqueles que integram a Região dos Lagos, Petrópolis, Niterói e Campos, o fizeram pela possibilidade de obter a titularidade dos serviços. Essa conquista representou uma oportunidade para o nível da administração local de efetuar uma cisão com o governo estadual. Em outros termos, essas iniciativas estabeleceram relações diretas entre poder local e empresas multinacionais ou consórcio de empresas, interessadas nessa atividade.

Em segundo lugar, esses municípios correspondem a áreas, de um modo geral, de grande visibilidade no estado. No conjunto, esses municípios exercem uma atração para os investimentos dessa natureza, seja pelo fato de que a imagem de eficiência dos serviços acaba por desdobrar-se em uma segunda imagem: a da eficiência da administração do serviço pela iniciativa privada, seja pelo mercado que representam.

Para as companhias de água e saneamento a natureza da atividade, a conectividade dos consumidores à rede de distribuição e a capacidade de mobilizar recursos financeiros para os investimentos necessários definem as práticas espaciais. Os atores institucionais optam por uma centralização das decisões em escalas mais amplas, porém, a capacidade de articulação dos atores locais vem se tornando a via mais adequada para inflexionar determinadas regras contratuais. Nesse sentido, a desconcentração dos serviços na escala municipal foi um elemento importante, mesmo que, na origem, não tenha sido pensado para tal. $\mathrm{O}$ regime de apropriação dos recursos hídricos é também uma questão de política pública de repartição equitável desse recurso. Em outros termos, condicionantes tecnológicos, econômicos e financeiros que interferem na estrutura da indústria não estão desvinculados das questões sobre apropriação dos recursos em geral, e dos recursos hídricos em particular, nem dos movimentos de base local.

\section{OS SERVIÇOS DE ÁGUA E ESGOTO NO ESTADO DO RIO DE JANEIRO: REGULAÇÃO E PRIVATIZAÇÃO}

Resumo: Este artigo explora as contradições do novo modelo institucional no Brasil, cuja implementação vem provocando mudanças significativas na posição dos municípios no que diz respeito ao controle dos serviços de água e saneamento. A partir da Lei 9.433/97, analisa-se as adaptações dos municípios ao novo quadro institucional. Argumenta-se que as mudanças propostas não garantem a competitividade na indústria de água e saneamento, pressuposto dos marcos regulatórios vigentes.

Palavras-Chave: política de recursos hídricos; concessões de água e saneamento, Rio de Janeiro: privatização dos serviços de água e esgoto. 
WATER AND SANITATION IN RIO DE JANEIRO STATE: REGULATION AND PRIVATIZATION

Abstract: This paper explores the contradictions in the new model of the water regulation in Brazil, which result in a re-configuration of the position of the municipalities in the water industry. We briefly outline the main changes introduced by the 9433 Law (Water Law) and analyze how the municipalities are adjusting themselves to this new order. The changes in the Rio de Janeiro water industry provide an example in which institutional shifts are no guarantees to produce competitiveness in the water industry.

Keywords: water policy, water supply and sanitation industry, Rio de Janeiro: water and sanitation privatization.

\section{BIBLIOGRAFIA}

ANGELIER, Jean-Pierre. (1991). Economie Industrielle: eléments de méthode. Grenoble : Presses Universitaires de Grenoble.

ANUÁRIO ESTATÍSTICO DO ESTADO DO RIO DE JANEIRO. (1981). Rio de Janeiro : Fundação de Amparo à Pesquisa do Estado do Rio de Janeiro.

ANUÁRIO ESTATÍSTICO DO ESTADO DO RIO DE JANEIRO. (2001) Rio de Janeiro: CIDE.

BARRAQUÉ, B. (2001): Les agences de l'eau françaises: un modele pour le Brésil? IV Diálogo Interamericano de Gerenciamento de Águas. Brasília: Ministério do Meio Ambiente/ secretaria de Recursos Hídricos. Inédito.

BNDES. (2003). Posição de Privatizações em Andamento: www.bndes.gov.br: em 07/02/2003.

BNDES/ FINAME. (1996). Saneamento Ambiental - Foco: Saneamento Básico 1. Cadernos de Infra-Estrutura: Fatos-Estratégias. Rio de Janeiro : BNDES / Área de Projetos de Infra-Estrutura Urbana, outubro.

BOYER, R. (1986). La théorie de la regulation: une anlyse critique. Paris : Éditions la Découverte.

BRITTO, A.L. e PORTO, H.R. (2000). Universalização e privatização: os dilemas da política de saneamento na metrópole do Rio de Janeiro. In: RIBEIRO, L.C.Q. (org). O futuro das metrópoles: desigualdades e governabilidade. Rio de Janeiro : Revan : FASE, pp. 457-478.

BRITTO, A.L., PORTO, H.R.L. (org). (1998). Serviços de saneamento da Baixada Fluminense - problemas e perspectivas. Rio de Janeiro : Observatório de Políticas Urbanas : IPPUR : FASE.

BRITTO, A.L.N.P. (1995). Modes de Gestion des Services d' Eau et d'Assainissement à Rio de Janeiro (1975-1986). Paris : Université de Paris XII, S.

BYATT, I.C.R. (1998). Competition in the Water and Sewerage Industry. In: HELM, D. and JENKINSON, T. (ed.). Competition in Regulated Industries. Oxford : Oxford University Press. 
COWAN, S. (1998). The Water Industry. In: HELM, D. And JENKINSON, T.(ed.): Competition in Regulated Industries. Oxford: Oxford University Press.

DANTAS, A., KERTSNETZKY, J. e PROCHNIK, V. (2002). Empresa, indústria e mercados. In: KUPFER, D. Economia industrial: fundamentos teóricos e práticos no Brasil. Rio de Janeiro: Campus, Pp. 23-41.

DUPUY, G. (1991). L'urbanisme des réseaux: théories et méthodes. Paris: Armand Colin.

GAZETA MERCANTIL. (1998). Análise Setorial: Saneamento Básico - Volume I. Panorama Setorial. Gazeta Mercantil, março.

GAZETA MERCANTIL. (2002). Relatório Anual de Empresas. São Paulo : Gazeta Mercantil, junho.

HALL, D. The Water Multinationals. PSIRU. Greenwich : University of Greenwich.

HESPANHOL, I. (1999). Água e Saneamento - Uma Visão Realista. In: REBOUÇAS, A.C. et al. Águas Doces no Brasil: capital ecológico, uso e conservação. São Paulo : Escrituras Editoras, 1999. pp. 249-303.

LEI 8.987, de 13 de fevereiro de 1995, que dispõe sobre regime de concessões e permissão da prestação de serviços públicos. Governo Federal.

LEI 9.433, de 8 de janeiro de 1997, que institui a Política Nacional de Recursos Hídricos e cria o Sistema Nacional de Gerenciamento de Recursos Hídricos. Conselho Nacional de Recursos Hídricos. Governo Federal.

LÉVEQUE, F.'(1998). Économie de la réglementation. Paris:Découverte.

MELLO, M.F. de. (2001). Privatização do setor de saneamento no Brasil: quatro experiências e muitas lições. Texto para Discussão $\mathrm{n}^{\circ}$ 447. Rio de Janeiro: PUC-Rio, Departamento de Economia, setembro.

PARLATORE, A.C. (2000). Privatização do Setor de Saneamento no Brasil. In: PINHEIRO, A.C. e FUKASAKU, K. A Privatização no Brasil: o caso dos serviços de utilidade pública. Rio de Janeiro:BNDES, 2000. pp. 279-320.

PESQUISA NACIONAL DE SANEAMENTO BÁSICO: 2000. (2002). Rio de Janeiro: IBGE.

PIRES do RIO, G.A., SALES, A.V.S. e MOURA, V.P. (2002). A indústria da água no Brasil: efeitos da política de privatização e as novas formas de organização. In: "2º SIMPORH - A Fronteira é Hídrica". Campo Grande:UFMG, julho.

PIRES do RIO, G.A. \& PEIXOTO, M.N.O. (2001). Superfície de Regulação e Conflitos de Atribuições na Gestão de Recursos Hídricos. In: Território, ano VI, $n^{\circ} 10$, jan/jun de 2001. pp. 55-65.

PIRES do RIO, G.A., PEIXOTO, M.N.O. e MOURA, V.P. (2001). Lei das Águas: desdobramentos para a gestão ambiental e territorial. In: MATA, S.F., GANAZZA, S., ALMEIDA, M.C.M. e BARROS, R.P. Educação Ambiental: projetivas do século. Rio de Janeiro: MZ Editora Ltda, Pp. 39-99. 
PROJETO DE LEI N²66/97. Institui diretrizes nacionais para o saneamento básico e dá outras providências. Secretaria de Assuntos Parlamentares. Congresso Nacional;

REES, J. (1998). Regulation and private Participation in the Water and Sanitation Sector. Natural Resource Forum 22 (2): 95-105.

SILVA, R.T. (2003). Infra-estrutura socioeconômica do estado de São Paulo e a dinâmica urbano-regional recente. Interações entre a organização da oferta de infra-estrutura no Brasil e as relações entre o público e o privado na gestão urbana e regional. In: GONÇALVES, M.F., BRANDÃO, C.A., GALVÃO, A.C.F.(orgs). Regiões e cidades, cidades nas regiões: o desafio urbano-regional. São Paulo: Editora UNESP:ANPUR, 2003. P: 131-154.

SOLANES, M. (1995). The privatization of public water utilities. CEPAL Review 56. 